\title{
Conflictes socioambientals i estudi de la percepció social del risc
}

\section{Josep Espluga Trenc}

Universitat Autònoma de Barcelona. Departament de Sociologia

08193 Bellaterra (Barcelona). Spain

joseplluis.espluga@uab.es

\section{Resum}

Larticle descriu diferents corrents teòrics d'estudi de la percepció social del risc, tot explicitant-ne els pressupòsits teòrics i metodològics, el seu abast i les seves limitacions. S'hi observa que aquest tipus d'investigacions pretenen esbrinar per què la gent de vegades posa en pràctica comportaments aparentment poc racionals o incongruents davant determinats riscos, la qual cosa sovint es manifesta en forma de conflictes socials. El debat acadèmic ha permès transcendir l'oposició entre risc objectiu i risc subjectiu que dominà les discussions en una primera època, per avançar cap a marcs teòrics més complexos, a partir dels quals es planteja que els conflictes socials tenen a veure amb l'existència de diferents concepcions del risc que competeixen per imposar-se en el debat social i polític.

Paraules clau: risc tecnològic, percepció social del risc, conflictes ambientals, relacions entre experts i profans.

\section{Resumen. Conflictos socioambientales y estudio de la percepción social del riesgo}

En el artículo se describen diferentes aproximaciones teóricas al estudio de la percepción social del riesgo, explicitando sus presupuestos teóricos y metodológicos, su alcance y sus limitaciones. Se observa que el propósito fundamental de este tipo de investigaciones es averiguar por qué la gente a veces pone en práctica comportamientos aparentemente inesperados o poco racionales ante determinados riesgos, lo cual a menudo acaba por generar conflictos sociales. El debate académico ha permitido trascender la oposición entre riesgo objetivo y riesgo subjetivo que dominó las discusiones en una primera época, para avanzar hacia marcos teóricos más complejos e integradores, a partir de los cuales se plantea que los conflictos sociales están relacionados con la existencia de diferentes concepciones del riesgo que compiten por imponerse en el debate social y político.

Palabras clave: riesgo tecnológico, percepción social del riesgo, conflictos ambientales, relaciones entre expertos y legos.

\section{Abstract. Socio-environmental conflicts and social perception of risk studies}

This article describes several theoretical approaches on social perceptions of risk, remarking their main theoretical and methodological frameworks and their limits. The main aim of these approaches is to know why sometimes people seem to cope with risks in an irrational way, frequently promoting social conflicts. The evolution of the academic debate allows it to overcome the classical objective risk / subjective risk oposition, in order to go to more complex and holistic theoretical frames, which establish that social conflicts of 
risk have something to do with the stock of different risk conceptions competing in the political and social debate.

Key words: technological risk, risk perceptions, environmental conflicts, experts/lays relationships.

\section{Sumari}

1. L'estudi de la percepció social del risc

2. El debat sobre el risc acceptable

3. Les aproximacions psicomètriques al risc

4. La percepció del risc des de la teoria cultural
5. Algunes perspectives més integradores i reflexives

6. Conclusions

Bibliografia

\section{L'estudi de la percepció social del risc}

La percepció social del risc és un terme desafortunat i excessivament reduccionista, però ha esdevingut un camp de recerca àmpliament elaborat i discutit des de diverses tradicions teòriques de les ciències socials durant les darreres tres dècades, sobre el qual s'han fet importants troballes que caldria no ignorar. Massa sovint, des d'institucions públiques i privades encarregades de gestionar riscos, es tendeix a pensar que els ciutadans i les ciutadanes protesten o s'oposen a determinades activitats o tecnologies perquè no coneixen prou bé el seu funcionament, i, de manera massa simplista, en dedueixen que caldria donar-los més i millor informació perquè així deixessin d'oposar-s'hi (tot acusant, de passada, els mitjans de comunicació per haver generat una mala imatge d'aquelles tecnologies o activitats). En el present text pretenem mostrar que aquest punt de vista ha estat àmpliament superat pels avenços teòrics i empírics en la investigació sobre la percepció i gestió dels riscos tecnològics.

Les investigacions socials sobre la percepció social del risc apareixen i es generalitzen sobretot a partir de la dècada de 1970 , i responen a la necessitat que certes institucions i empreses tenen de comprendre i mitigar les protestes ciutadanes envers noves tecnologies o activitats (com ara l'energia nuclear, certes instal-lacions químiques, abocadors de residus industrials, aplicacions biotecnològiques, etc.). Malgrat el sostingut increment del benestar material i de l'esperança de vida en els països occidentals, nombrosos estudis han mostrat (Amato, 1995; Tàbara, 1995) que la major part dels ciutadans opinen que es troben sotmesos a molts més riscos avui que en el passat, i que els riscos futurs seran encara més grans que els actuals. Això revela un creixent allunyament entre les preocupacions dels ciutadans i les prioritats definides pels experts, la qual cosa genera dificultats serioses en la gestió dels riscos. Per això, els encarregats de la presa de decisions (polítics, gestors, directius d'empreses, etc.) han considerat cada cop més necessari intentar entendre de quina manera la gent 
considera els riscos i quins comportaments individuals i col-lectius posen o poden posar en pràctica al respecte ${ }^{1}$.

El paradigma de presa de decisions davant els riscos predominant a la societat capitalista industrial es caracteritza per ser eminentment tecnocràtic. L'anàlisi dels riscos consisteix en l'aplicació, per part d'experts, de procediments i mètodes basats en un pressupòsit de causalitat lineal i en dades estimades sobre fets objectius. A través de càlculs i valoracions avalats per mètodes científics, en funció de paràmetres com les probabilitats que succeeixin els possibles danys i com les seves possibles magnituds o consequiències, els experts poden valorar els riscos que aquelles tecnologies comporten. Des d'aquest model, l'avaluació i la gestió dels riscos es consideren dues activitats teòricament separades: la primera «neutral» i destinada a proporcionar dades «objectives»; la segona, la presa de decisions, orientada per la primera, però mínimament oberta a la inclusió d'algunes consideracions "polítiques». Malgrat tot, els experts i els decisors observen que els individus que es perceben exposats a aquelles tecnologies, $\mathrm{i}$ el públic en general, no sempre posen en pràctica uns comportaments adecuats, bé perquè sobreestimen el risc i exerceixen una forta oposició a la implantació d'aquelles tecnologies, o bé perquè el subestimen i adopten comportaments arriscats i aparentment irresponsables.

Quan aquestes situacions, especialment les de rebuig a certes tecnologies, es començaren a generalitzar, entre les dècades de 1960 i 1970, es considerà prioritari identificar la percepció del risc que tenien els individus per tal de poder prendre decisions encaminades a pal-liar el biaix existent entre ells i els experts. Això propicià l'aparició del concepte de risc acceptable, sota el supòsit que es podria identificar el llindar a partir del qual els individus que fessin un càlcul racional dels seus costos i beneficis deixarien d'oposar-se a aquelles instal-lacions perilloses i a aquells suposats riscos. Més endavant, durant els anys vuitanta, assolí importància la investigació sobre la comunicació del risc, ja que, a ulls d'experts i decisors, apareixia com a evident que, per tal que la gent deixés de tenir aquelles creences inadequades o irracionals, se'ls havia d'informar correctament sobre la bondat de les investigacions i les anàlisis tècniques sobre els riscos. No és fins a finals de la dècada de 1980 i durant la de 1990 quan es comença a posar l'èmfasi en perspectives de caràcter més integrador que tenen en compte el marc social, polític i cultural en el qual tenen lloc els processos de percepció i comunicació dels riscos. A més a més, durant els anys noranta, al caliu dels debats teòrics sobre la societat del risc (Beck, Giddens, etc.), comença a sorgir com a àrea prioritària d'investigació la percepció dels riscos ambientals vinculats amb la contaminació difusa i l'esgotament dels recursos naturals i caracteritzats per un impacte de tipus més crònic, irreversible, acumulatiu i global sobre les condicions de vida en el planeta.

1. Les protestes i mobilitzacions ciutadanes contra certes tecnologies poden arribar a bloquejar-ne la difusió i a fer replantejar-ne el model de gestió. Un cas paradigmàtic són les recents respostes socials a les antenes de telefonia mòbil. Es pot veure una anàlisi detallada d'aquest conflicte social a Espluga (2002). 


\section{El debat sobre el risc acceptable}

Els primers treballs sobre percepció del risc, a principis dels anys setanta, intentaven esbrinar els biaixos cognitius que la gent tenia respecte als judicis experts sobre els riscos originats per diverses tecnologies. Es pensava que un cop coneguts aquests biaixos es podria fer que aquestes persones duguessin a terme comprensions més adequades d'aquells fenòmens. No cal dir que per «comprensions adequades» s'entenia només aquelles que coincidissin amb les formulades pels experts. La investigació sobre percepció del risc tenia l'objectiu d'identificar objectivament un nivell de risc acceptable que ajudés a la gestió de tecnologies perilloses. En aquest context, es parteix de la consideració que la gent sovint posa en pràctica comportaments poc racionals a causa de la seva «ignorància» tècnica, $\mathrm{i}$ les solucions que se'n deriven acostumen a consistir a intentar informar i educar la gent sobre els riscos reals, sovint mitjançant uns processos comunicatius unidireccionals.

El concepte de risc acceptable implica la possibilitat d'establir un criteri o un llindar de risc que permeti prendre decisions i, fins i tot, legislar sobre l'acceptabilitat de distintes tecnologies o activitats en funció del nivell de risc generat per cadascuna, tot tenint en compte els beneficis que comporten. How safety is safe enough? ('Quanta seguretat serà suficient?') ha estat la pregunta clàssica que ha promogut tot aquest tipus d'investigació. Els experts i decisors han dedicat importants recursos i esforços durant les darreres dècades per tal de trobar, per progressives eliminacions, un tipus de risc universalment acceptable i científicament indiscutible. Però, sovint, les definicions del risc que acompleixen aquestes característiques acostumen a ser uns tipus ideals que resulten tan irreals o òbvies que difícilment poden tenir una concreció en la pràctica ${ }^{2}$.

Hi ha consens entre la bibliografia a considerar que el debat sobre el risc acceptable començà amb l'article de Starr (1969) publicat a la revista Science, qui efectuà un estudi sobre l'acceptabilitat social de distintes fonts de risc i desenvolupà un mètode d'avaluació del nivell acceptat de risc en relació amb els beneficis produïts per la tecnologia. Amb aquesta proposta, Starr intentà oferir unes bases científiques per establir llindars de risc acceptable que poguessin ser usats normativament en la presa de decisions. Per fer-ho, va construir un mètode basat en el que ell anomenà "preferències revelades» $\mathrm{o}$, més aviat, "tàcites» (revealed preferences). A partir de l'observació i constatació del que la gent fa, en deduí una sèrie de preferències, i suposà que, a través de proves i errors, la societat és capaç d'assolir un equilibri òptim entre els riscos i els beneficis associats a cada activitat o tecnologia. Per exemple, si durant un període determinat la gent no insisteix ni protesta pels riscos derivats dels automòbils, la taxa de mortalitat

2. Per exemple el definit per Munn (1975; citat per Amendola, 1991: 35) és una bona mostra de la reducció a l'absurd a la qual es pot arribar en la cerca del risc acceptable objectiu: «Un risc acceptable és aquell, la probabilitat del qual és tan petita, i les conseqüències del qual són tan lleugeres, o els beneficis del qual (percebuts i reals) són tan grans, que una persona, grup o societat està disposada a assumir-lo». 
anual en automòbil es podrà considerar com l'acceptada per la societat i, per tant, serà un indicador del nivell de risc acceptable. Starr argumentava que «la societat» estableix un nivell acceptable de risc mitjançant una contrastació permanent entre danys i beneficis, de tal manera que com més beneficis generi una activitat, més acceptable serà el risc associat a aquesta activitat.

Des d'aquesta perspectiva, Starr proposà investigar les bases de dades sobre riscos i beneficis de nombroses tecnologies i activitats industrials, per tal de posar de manifest les regularitats o patrons d'intercanvi entre riscos acceptats i beneficis. A partir d'aquestes dades empíriques, observà que els riscos assumits voluntàriament (com ara conduir, esquiar o nedar) presentaven uns nivells d'acceptabilitat molt més alts que els riscos imposats (com ara els estàndards de qualitat de l'aire o els residus radioactius) i d'això n’intentà fer una llei universal.

Aquests plantejaments de Starr aviat foren contestats i rebatuts des de diversos punts de vista. Otway i altres (1975) varen replicar Starr que les seves dades empíriques eren poc consistents i, a més a més, qüestionaren durament algunes de les assumpcions subjacents a les "preferències» que ell atribuïa a la «societat", en especial la suposició que pel fet que la gent no protesti activament contra els nivells de risc d'alguna tecnologia en particular, això hagi de significar que els accepta. Aquests autors també posen en qüestió la validesa de la distinció entre riscos voluntaris i involuntaris, ja que hi ha riscos que per a algunes persones poden ser assumits voluntàriament, mentre que per a altres persones poden ser inevitables (per exemple conduir). Per altra banda, s'observa que hi ha riscos que, malgrat que són considerats socialment inacceptables, són tranquil.lament acceptats pels individus concrets (com ara el tabac o el trànsit). En aquest sentit, és important distingir entre els nivells de risc que una persona està disposada a acceptar en les seves activitats quotidianes i els nivells que la col-lectivitat està disposada a acceptar com un dels costos associats a la generació d'un bé públic, cosa que el marc teòric proposat per Starr no contemplava. Efectivament, existeix una sensible diferència entre allò que un individu decideix per a si mateix i allò que creu convenient per a la col-lectivitat. Oppe (1988) s'adona que ell és capaç de treballar com a expert investigador en qüestions de seguretat i establir quins riscos resulten inacceptables, i al mateix temps no perdre la seva racionalitat quan personalment decideix, per exemple, acceptar aquells mateixos riscos com a conductor d'automòbil o com a fumador. Es tracta d'un dilema fonamental que obliga a tenir en compte factors com ara el context social d'interacció, els rols dels actors implicats o les institucions encarregades de gestionar el risc, entre altres coses (que la proposta de Starr no contemplava).

No obstant això, la crítica fonamental que s'ha formulat al concepte de risc acceptable rau en la consideració que allò que la gent accepta no són riscos, sinó opcions, i que el risc és només una característica, entre altres, que la gent té en compte a l'hora d'avaluar i triar entre aquelles opcions (Fischhoff $\mathrm{i}$ altres, 1981). Quan uns ciutadans jutgen un risc tecnològic determinat, no només tenen en compte els possibles danys que aquest pot causar, sinó que també valoren molts altres factors associats a aquella activitat o tecnologia (com afec- 
tarà les seves vides quotidianes, quines alternatives tenen, etc.) $)^{3}$. A més a més, que una persona tingui una elevada percepció de risc respecte a una activitat o tecnologia, no vol dir necessàriament que la rebutgi amb més èmfasi, ni que el seu grau d'acceptació sigui menor. La relació entre percepció del risc i acceptabilitat no és directament proporcional ni estrictament causal. És possible, per exemple, que tot i que la magnitud del risc percebuda sigui petita, la font es consideri inacceptable per altres raons o factors (com altres alternatives a escollir, factors del context polític i social, credibilitat de les institucions que el gestionen, etc.).

\section{Les aproximacions psicomètriques al risc}

Un dels corrents d'investigació social més influents des de finals dels anys setanta es coneix amb el nom d'enfocament psicomètric (psychometric approach). Impulsat i representat principalment per P. Slovic, B. Fischhoff i els investigadors de l'anomenat Grup d'Oregon (Decision Research Oregon), tracta de resoldre algunes de les deficiències metodològiques i conceptuals de la proposta de Starr, per a la qual cosa proposaren estudiar la percepció i l'acceptabilitat social dels riscos a través de les "preferències expressades» per la gent i no de les observades «implícites». En aquest sentit, els investigadors del psychometric approach han tractat d'identificar les preferències dels individus a partir d'experiments controlats en grups de persones d'orígens socials diferents, amb l'objectiu d'esbrinar els diversos atributs dels riscos que fan que, malgrat que tinguin una mateixa freqüència de mortalitat o de danys, la gent els atorgui més o menys pes.

L'enfocament psicomètric constitueix la perspectiva més prolífica en l'estudi de la percepció social del risc. Aquest corrent parteix de la tradició de la psicologia cognitiva i de les teories de la decisió racional i, a més a més, incorpora una concepció multidimensional del risc (en el sentit que es considera que les possibles conseqüències dels riscos no són només danys físics, sinó també altres coses com ara danys psicològics, pors, temors, pèrdues socials, etc.). Els estudis psicomètrics comprovaren que la gent introduïa en els seus judicis altres elements més enllà de les dades estrictament científiques, amb la qual cosa les divergències entre les avaluacions dels experts i les percepcions de la gent no tenien a veure només amb la ignorància de les probabilitats i magnituds del risc (definides pels científics), sinó que també hi havia altres elements que els segons tenien en compte i els primers, no. La recerca se centrà a descobrir quins

3. És possible, per exemple, que una persona visqui en una casa construïda amb materials contaminants, com asbestos, i que conegui perfectament els efectes perjudicials que poden ocasionar a la seva salut, però que no pugui canviar d'habitatge perquè qualsevol altra opció al seu abast sigui pitjor (perquè no té diners per canviar-se, perquè traslladar-se a un altre territori l'obligaria a canviar de feina, a perdre contacte amb familiars, etc.). El risc de l'asbest és simplement una cosa més que ha de tenir en compte a l'hora de valorar la seva situació i decidir les seves accions. 
eren aquests altres elements o atributs del risc i a desenvolupar una taxonomia de riscos que pogués ser utilitzada per entendre i predir la forma com la societat hi respon (Slovic i altres, 1984). Des d'aquest enfocament es treballa amb qüestionaris que inclouen llistes de diversos factors de risc per tal que els individus els avaluïn (els donin una puntuació), tant pel que fa a la dimensió quantitativa de risc percebut en general, com pel que fa a les diverses característiques qualitatives associades a cada risc. Els resultats dels seus treballs empírics, per exemple, han demostrat que, contràriament al que proposava Starr, no hi ha a penes correlació entre els riscos i els beneficis percebuts. D'altra banda, mentre Starr concloïa que la voluntarietat de l'exposició al risc era la clau de l'acceptació del risc, els estudis del paradigma psicomètric han mostrat que hi pot haver altres factors igualment influents. Així, per exemple, Fischhoff i altres (1978) varen llistar els atributs bàsics següents:

- Voluntarietat / involuntarietat de l'exposició.

- Immediatesa / demora dels efectes.

- Coneixement / desconeixement del risc per part de la persona exposada.

- Coneixement / desconeixement per part de la ciència.

- Controlabilitat / incontrolabilitat sobre el risc.

- Novetat / antiguitat del risc.

- Danys catastròfics / danys crònics potencials.

- Més o menys temor.

- Gravetat més o menys gran de les conseqüències.

Tots aquests atributs són entesos com a propietats qualitatives del risc i representen dimensions emocionals i cognitives, i des d'aquest enfocament es consideren caracteristiques universals de la percepció del risc, tot i que en cada situació concreta la gent els pot atribuir un pes diferent ${ }^{4}$. Mitjançant nombroses investigacions, s'elaboraren altres llistes de categories o atributs, més o menys similars a aquest ${ }^{5}$, però alguns autors aviat advertiren que mai no es podrà arribar a llistar un conjunt complet i generalitzable, ja que aquests atributs poden ser qualsevol cosa que la gent hagi après a associar amb la tecnologia (Otway i Von Winterfeld, 1982) ${ }^{6}$.

4. Altres autors han proposat llistes de les categories que poden estar més relacionades amb l'acceptabilitat del risc. Així, Vlek i Stallen (1980) apunten una llista d'onze categories: voluntarietat de l'exposició, controlabilitat de les consequiències, distribució de les conseqüències en el temps, distribució de les conseqüències en l'espai, context de l'avaluació de la probabilitat, context de l'avaluació de la valoració del dany, combinació de la probabilitat i la gravetat del dany, coneixement de l'activitat, condicions dels subjectes, consideracions socials, confiança en els experts i/o legisladors.

5. Pidgeon i altres (1992) adapten les categories d'Otway i Von Winterfeld i les recullen en una taula sobre "Atributs (negatius) de les fonts de perill que influeixen en l'acceptació i percepció del risc». Per una més àmplia descripció i síntesi de totes aquestes llistes, així com per veure l'aplicació d'aquests mètodes a Espanya, es pot consultar l'obra Percepción social de los riesgos, de Puy (1995).

6. Que les valoracions del risc fetes per experts difereixen en gran mesura de les del públic llec ha estat àmpliament provat pels investigadors del Grup d'Oregó (Lichtenstein i altres, 1978; 
Però el concepte de risc que utilitza l'enfocament psicomètric també té unes limitacions. Turner i Wynne (1992) argumenten que molts dels atributs identificats en el risc, com ara la controlabilitat, la familiaritat o l'equitat en la seva distribució, seria millor interpretar-los com a propietats inherents a les estructures socials i institucionals dels processos de generació del risc, més que no pas al risc en si. És a dir, mentre l'enfocament psicomètric pressuposa que la gent reacciona davant les propietats o els atributs dels riscos, Turner i Wynne (1992) sostenen que les respostes del públic haurien de ser enteses més aviat com a indicadors de la no-acceptació de tecnologies, o dels gestors de les tecnologies, més que no pas dels riscos per se. En el fons, el que aquests autors qüestionen és que el paradigma psicomètric assumeix massa facilment que els riscos tenen una existència objectiva independent dels complexos contextos socials en els quals la gent els experimenta.

Una altra de les limitacions que s'atribueix a aquesta perspectiva (Renn, 1992) és que l'amplitud o diversitat de les dimensions que els individus usen per formular els seus judicis, i la seva dependència d'heurístics intuïtius i de coneixement anecdòtic, fa difícil d'agregar les preferències individuals i el fet de buscar un comú denominador que permeti comparar percepcions individuals del risc. Una altra limitació, de caire metodològic, és que aquests estudis quantitatius sobre les percepcions del risc donen per descomptat que tothom entén el mateix quan li parlen d'un risc, sense qüestionar primer si la gent participa o no d'aquell significat ${ }^{7}$.

\section{La percepció del risc des de la teoria cultural}

Antropòlegs i sociòlegs han observat que diferents grups socials i culturals atorguen una importància diferent a diferents riscos, i desenvolupen unes actituds i uns comportaments que es corresponen amb aquelles formes d'entendre els riscos. Per tal d'intentar explicar aquest fenomen, els estudis culturals sobre el risc combinen enfocaments teòrics de caire estructuralista i constructivista. En aquesta perspectiva, cal destacar les aportacions de la teoria cultural (Douglas i Wildavsky, 1982; Dake, 1991; Rayner, 1990; etc.), la qual té el seu principal exponent en el llibre de Mary Douglas i Aaron Wildavsky Risk and Culture (1982). Des d'aquesta perspectiva, es considera que les creences, les actituds i

Slovic, 1987), els quals, en els seus estudis empírics, han trobat que, si bé les valoracions sobre la magnitud del risc realitzats pels experts s'ajusten bastant bé a les estimacions tècniques sobre taxes de mortalitat esperada, les valoracions del públic profa resulten sempre més allunyats d'aquestes estimacions tècniques. Això ratificaria que els experts consideren el risc com alguna cosa molt relacionada amb les taxes de mortalitat, mentre que el públic profa hi inclou altres dimensions.

7. En aquesta línia crítica, Wynne (1992a) suggereix que una de les activitats més frequients en el camp de l'estudi del risc, com ara mesurar les actituds de la població vers els riscos, sovint no és més que un joc enganyós i inútil perquè abans de pensar a mesurar actituds primerament s'hauria d'intentar comprendre els significats que les persones atribueixen al risc concret. 
els valors compartits per determinats grups (institucions, grups socials, grups culturals) incideixen en la selecció d'allò que aquests consideraran o no com un risc, i, per tant, les persones es preocuparan especialment per aquells esdeveniments o aspectes que més poden afectar o posar en perill els seus sistemes de creences i valors, la seva manera d'entendre i viure les relacions socials. Amb aquests pressupòsits, la intenció de la teoria cultural del risc no és tant donar resposta a quins riscos ens provoquen més o menys por, sinó esbrinar quin tipus de grups socials es preocupen d'uns determinats riscos i per què. És a dir, explicar per què en una mateixa societat hi ha grups que difereixen molt a l'hora d'atorgar importància a uns mateixos riscos (per això, des d'aquesta perspectiva, es considera improcedent preguntar-se per un nivell global de risc acceptable o de seguretat suficient).

Douglas (1996) considera que bona part de la investigació sobre percepció del risc s'ha aplicat, equivocadament, als individus en lloc de a les institucions. Des d'aquest corrent teòric, se suposa que les creences sobre la natura i sobre els riscos són construïdes (i seleccionades) socialment amb la finalitat implícita de mantenir la coherència grupal o institucional (de mantenir uns models de relacions socials predominants, o ideals). Els sistemes de creences són vistos com expressions tàcites dels valors socials dominants i serveixen per bastir unes estructures socials que es presenten als individus com si fossin naturals $\mathrm{i}$ inevitables. Les institucions (o grups) seleccionen i utilitzen els riscos per controlar la incertesa de la conducta humana, per reforçar les normes i facilitar la coordinació interna del grup. Segons Douglas (1996), l'amenaça d'una catàstrofe compleix la funció d'activar certs mecanismes per renovar el compromís dels membres amb els objectius de l'organització. Així, per exemple, s'apel.la a la fragilitat o vulnerabilitat de la naturalesa com a forma per cohesionar el grup social o la institució mitjançant la inculpació d'un enemic extern al grup. El risc és, doncs, un mecanisme de coacció per assegurar la submissió dels membres al sistema, i els riscos reconeguts exerceixen funcions de manteniment d'aquest sistema.

Douglas i Wildavsky (1982) aplicaren ${ }^{8}$ aquest marc teòric a les percepcions del risc en la societat nord-americana i observaren que, en els debats sobre el risc

8. Les observacions de la teoria cultural de Douglas i Wildavsky s'estructuren a partir d'un esquema analític conegut com "anàlisi grup/xarxa» (grid/group analysis) (Douglas i Wildavsky, 1982: 138-151), on consideren que els elements que determinen les cosmologies del risc són constituïts per dues dimensions ortogonals que permeten quatre tipus bàsics de contextos socials: la dimensió grup es refereix a la força de la identitat grupal per determinar els límits entre el grup i el món exterior, és a dir, al grau d'identificació d'una persona amb un grup social determinat; mentre que la dimensió xarxa (o jerarquia) fa referència a com el poder està distribuït dins el grup, a les delegacions d'autoritat per les quals els individus es limiten els uns als altres en les seves interaccions quotidianes (normes socials i sancions), és a dir, el grau d'acceptació d'un sistema de relacions més o menys jeràrquic. Douglas i Wildavsky suggereixen quatre possibles «cultures» en funció de la combinació dels valors d'aquestes dues dimensions: cultura jeràrquica, cultura igualitària, cultura individualista i alienació. La percepció del risc i els comportaments de la gent respecte als riscos estaran relacionats amb la seva socialització en alguna d'aquestes tipologies culturals. 
durant la dècada de 1970, diferents grups socials emfatitzaven no només diferents atributs del risc, sinó també diferents tipus de riscos, fins i tot quan aparentment discutien o argumentaven sobre el mateix problema. Els autors suposaren que aquestes diferències bàsiques en la selecció del risc podien ser atribuïdes a diferents formes d'organització social dels grups implicats, així com als seus diferents tipus d'interacció en la cultura política general ${ }^{9}$. Des del seu punt de vista, cada grup social selecciona (inadvertidament) els riscos que "vol» témer amb la finalitat de donar coherència a la seva forma de viure i als seus propis valors per augmentar la solidaritat interna als grups i a les institucions, $i$ ignora la resta dels possibles riscos (que sí que poden ser rellevants per a uns altres grups socials).

Entre les crítiques que es fa a aquest esquema analític del risc, destaca la dificultat per ser aplicat empíricament, ja que, per una banda, és molt difícil determinar a quin nivell d'organització social es pot aplicar (grups petits o grans societats) i no resulta facil encabir-hi situacions reals. En aquest sentit, es pot dir que no hi ha consens entre els autors d'aquesta teoria sobre com fer per decidir si uns individus concrets formen part d'un grup o un altre o d'institucions amb cultures diferents, ni si un individu pot pertànyer al mateix temps a més d'un grup ${ }^{10}$. Com a conclusió, cal remarcar que es tracta d'un esquema força rígid, que deixa poc marge a l'acció reflexiva dels individus i que, en certa manera, pressuposa una realitat estàtica. No obstant això, pel que fa al tema que ens ocupa, té la virtut de proposar una explicació sobre la percepció del risc basada en els sistemes de valors compartits per grups de persones i contribueix a explicar les limitacions de les perspectives que privilegien sense matisos les decisions dels experts en els processos de risc.

\section{Algunes perspectives més integradores i reflexives}

A continuació es descriuen algunes perspectives teòriques que han intentat desenvolupar un marc teòric més ampli i integrador, tot recollint algunes de les propostes anteriors articulades en uns models que tenen més en compte els contextos d'interacció particulars i els processos psicosocials i contextuals en els quals la gent experimenta els riscos.

9. Per exemple, en un dels seus estudis, els membres dels grups ecologistes tendien a emfatitzar riscos catastròfics amb conseqüències a llarg termini; els empresaris es preocupaven sobretot dels riscos relatius al subministrament d'energia, així com de la continuïtat del consum i del desenvolupament econòmic; mentre que els buròcrates d'institucions reguladores es preocupaven bàsicament pels riscos que podien ser quantificats i sotmesos a programes de control i gestió (Douglas i Wildavsky, 1982).

10. Alguns autors, com la pròpia Douglas, proposen una interpretació rígida i entenen que la pertinença a una cultura és una característica permanent de la persona. Altres autors, com ara Wildavsky, han acabat per considerar que cada individu pot ser adscrit a diferents cultures en funció de cada context d'interacció social concret on es trobi. 


\section{a) Aportacions des de la psicologia social}

Des de la psicologia social, alguns autors han analitzat les interaccions entre l'entorn social (valors, creences, normes) i els judicis individuals sobre el risc. Els estudis realitzats per Otway, Von Winterfeldt i altres autors des de principis dels anys setanta, des de l'IIASA/IAEA (International Institute for Applied Systems Analysis / International Atomic Energy Authority) de Viena, són una de les mostres més interessants d'aquest tipus de perspectiva. Otway es basa en un marc teòric format per les teories sobre actituds, juntament amb la teoria de Fischbein de l'expectativa valor, que es podria resumir de la manera següent (Otway i Fischbein, 1976): les actituds de les persones envers un risc són determinades principalment per dos tipus de factors, per una banda, per les creences que tenen sobre la tecnologia o activitat generadora de risc que es tracti, $i$, per una altra banda, pels valors mitjançant els quals aquelles persones donen sentit operatiu a aquelles creences. Aquests investigadors centren les seves anàlisis a esbrinar com els individus mantenen o rebutgen determinats sistemes de valors i creences, ja que suposen que les actituds dels individus respecte als riscos i tecnologies formen part dels models amb els quals conformen la seva identitat individual i social ${ }^{11}$.

Des d'aquesta perspectiva, no es pot mantenir la suposició que les percepcions dels riscos es fonamentin en uns atributs objectius universals, tal com assumia el paradigma psicomètric, ni tampoc en uns beneficis socialment definits, com pressuposava Starr. El que caldrà tenir en compte serà l'existència de diferents models d'actituds, originats per la diferent procedència social dels individus i, a més a més, caldrà tenir en compte també els específics contextos socials i polítics en els quals la gent experimenta els riscos. Otway i altres autors defensors d'aquest marc teòric de caire psicosocial han intentat demostrar que l'existència de diferents percepcions del risc entre individus de diferents grups socials, té molt a veure amb l'existència de diferents creences sobre la tecnologia o l'activitat que origina el risc en concret. Unes creences integrades en amplis sistemes de valors, amb els quals els diferents grups intenten mantenir la consistència de les seves identitats socials.

S'ha qüestionat Otway perquè ha realitzat la major part de les seves anàlisis empíriques sobre la percepció dels riscos nuclears, uns riscos tecnològics que sovint comporten unes implicacions polítiques i unes respostes socials especialment sensibles, que no es donen en altres tecnologies. No obstant això, cal assenyalar que aporta un marc teòric interessant, que permet explicar l'existència, en una mateixa societat, de judicis i valors socials completament contradictoris subjacents a les percepcions del risc.

11. En aquesta línia, en l'àmbit ibèric, les investigacions desenvolupades a Tarragona per Gutiérrez i altres $(1991,1993)$ s'han interessat per mesurar les actituds de la població envers l'energia nuclear i la indústria petroquímica. 


\section{b) El marc teòric de l'amplificació social del risc}

Cal fer esment també d'una perspectiva integradora que intenta explicar alguns aspectes de la percepció i la comunicació del risc: l'amplificació social del risc. És un model desenvolupat pels investigadors de la Clark University (Kasperson, Kates, Renn, i altres), de la University of East Anglia (Pidgeon) i per alguns autors de l'enfocament psicomètric del Decision Research d'Oregon (Slovic i altres). El concepte d'amplificació social del risc es basa en la tesi que els esdeveniments relacionats amb riscos interactuen amb processos psicològics, socials, institucionals i culturals, de tal manera que poden augmentar o atenuar les percepcions del risc, així com donar forma als comportaments davant el risc (Kasperson i altres, 1988).

Segons aquest model, el procés d'amplificació social del risc comença amb algun esdeveniment (per exemple, un accident) o amb algun informe sobre possibles danys ambientals o a la salut. Alguns grups o individus els posen a la seva agenda, en seleccionen aquelles característiques específiques que s'adapten a les seves percepcions i esquemes mentals, i comuniquen les seves interpretacions a uns altres individus i grups. Finalment, reben interpretacions de retorn, amb la qual cosa alguns poden canviar les seves creences prèvies, guanyar coneixements i perspicàcies addicionals o ser motivats per passar a l'acció; uns altres poden refermar els seus punts de vista, i uns altres recompondre noves interpretacions i reenviar-les a les fonts o a d'altres parts interessades. En recollir informació sobre riscos i comunicar-la a uns altres (explícitament o implícitament), els individus, institucions o grups actuen com a estacions d'amplificació. Les unitats o grups socials grans actuen com a estacions socials d'amplificació (Kasperson, 1992).

Fins ara s'ha utilitzat l'amplificació social del risc per estudiar processos de comunicació del risc i per explorar les relacions entre les respostes individuals, socials i polítiques. Aquest marc de treball és un model dinàmic que es diferencia dels tradicionals models de comunicació basats en la simple transmissió d'informació entre un receptor i un emissor, i que centra l'atenció en els mecanismes d'amplificació que poden produir canvis en els missatges (Renn, 1991). No obstant això, sovint s'acusa aquesta teoria de ser massa genèrica i de resultar poc explicativa per a casos concrets, així com de no possibilitar la intervenció en la realitat.

\section{c) La perspectiva reflexiva de Brian Wynne}

Un tipus especialment interessant d'investigació sociològica sobre la percepció social del risc és la proposada pel sociòleg Brian Wynne, del Centre for the Study of Environmental Change (Lancaster University). La seva perspectiva pretén demostrar la importància del context social i institucional en el qual s'experimenta el risc a l'hora de valorar les percepcions i entendre els comportaments de les persones que s'hi senten exposades. L'aproximació teòrica proposada per Wynne recull, de manera eminentment crítica, algunes aportacions de la psicologia social d'Otway, certs trets de la teoria cultural de Douglas, 
algunes de les reflexions sobre la modernitat de Giddens i Beck, així com algunes assumpcions de la sociologia del coneixement científic. Des dels plantejaments proposats per Wynne (1992a), els riscos són definits socialment d'acord amb el grau d'amenaça percebuda per a les relacions socials i les pràctiques quotidianes, i no d'acord amb magnituds numèriques de danys físics, ni tampoc amb uns atributs universals del risc. En aquest sentit, Wynne insisteix a considerar que un dels factors essencials que influeixen en la percepció social del risc és la voluntat de les persones de mantenir, o de triar voluntàriament, un determinat teixit de relacions socials, uns estils de vida, unes afiliacions a determinats grups socials, unes identitats socials, en definitiva.

Des d'aquesta perspectiva, la investigació sobre la percepció del risc no hauria de dedicar-se tant a identificar les percepcions del risc real o objectiu, sinó a esbrinar les racionalitats de la vida quotidiana des de les quals els riscos, les activitats que els generen i les institucions que els gestionen, són identificats i experimentats per la gent (Turner i Wynne, 1992). Això implica també que els estudis realitzats des d'aquesta perspectiva han de tenir molt en compte la posició social dels agents implicats en la gestió del risc, la seva posició en l'estructura social, els seus recursos i les seves relacions de poder. Així, per exemple, en un dels seus primers estudis, Wynne $(1980,1982)$ investiga, mitjançant observació participant, un cas de conflictes socials relacionats amb la potencial contaminació generada per la planta tecnològica Windscale (Sellafield-Windscale Nuclear Complex), a la Gran Bretanya, i conclou que un dels principals factors que la gent tenia en compte per valorar el risc al qual es percebia exposada era la seva percepció dels agents controladors (funcionaris del govern, tècnics de seguretat, etc.): si aquells agents eren percebuts com a secretistes, arrogants o incompetents, sovint la gent feia una avaluació del risc molt més elevada del que indicaven els càlculs experts.

Diversos autors, com ara Giddens (1993, 1995), Bauman (1991) o Beck (1992, 1998), els quals estudien les conseqüències de la modernitat i teoritzen sobre la societat del risc, atribueixen al coneixement cientific i als sistemes experts un paper central en els processos de transformació de la societat actual. Tot i reconèixer la seva importància, Wynne considera que aquests autors magnifiquen la influència dels experts sobre el públic i en canvi dediquen poca atenció a l'estudi del que fa i pensa la gent. En aquest sentit, suggereix que caldria tenir més en compte els processos reflexius que els individus desenvolupen al respecte. Mitjançant els seus estudis empírics, Wynne observa que la gent, contínuament i de manera informal, problematitza les seves pròpies relacions amb experts de tot tipus, com una part del procés d'inacabable negociació de les seves identitats socials. La gent és conscient de la seva dependència i de la seva (major o menor) manca d'agència, i és precisament la consciència d'aquestes condicions el que ocasiona ansietat i sentit de risc en unes determinades persones o poblacions ${ }^{12}$. Aquest és un dels trets més característics de

12. A conclusions molt similars havien arribat també alguns autors (Vlek i Stallen, 1980; Stallen i Tomas, 1988) que han estudiat les diferències entre la gestió individual del risc i la gestió 
l'obra de Wynne: la comparació, tot situant-los en un mateix nivell d'importància teòrica, dels punts de vista dels experts i dels llecs (o profans). Per a Wynne (1996), entre ciutadans i sistemes experts hi ha una relació d'interdependència mútua, la qual cosa, al seu parer, té algunes implicacions importants: en primer lloc, és un error considerar que la desconfiança del públic respecte als experts només es produeix quan els individus perceben discrepàncies evidents entre aquests (respecte a algun tema de risc). En segon lloc, tampoc no és correcte pensar que en aquelles situacions en les quals no s'observa una resposta social d'oposició pública, s'hagi d'entendre que existeix una confiança en els experts ${ }^{13}$. Wynne observa també que, en general, la gent acostuma a desenvolupar una gran capacitat d'adaptació a les situacions de dependència de les institucions expertes. Sovint, els individus exposats al risc han de comportar-se com si realment confiessin en els experts, ja que els seria socialment i psicològicament difícil fer cap altra cosa, almenys mentre es vegin a si mateixos tan dependents d'ells ${ }^{14}$.

Wynne (1996) argumenta també que les percepcions públiques i les respostes al risc es fonamenten en judicis racionals sobre la conducta de les institucions expertes i sobre la seva capacitat de ser dignes de confiança (trustworthiness), especialment pel que fa a aquelles institucions que el públic suposa implicades en els processos de control del risc. En aquest sentit, es pot dir que les percepcions socials del risc impliquen algun element de judici sobre la qualitat de les institucions implicades, o, en altres paraules, dels rols dels diferents agents socials involucrats en els processos de risc, incloses les pròpies relacions amb ells. Aquests judicis no se circumscriuen només a la dependència (no volguda) que els individus i grups socials poden sentir respecte d'aquelles institucions, sinó que impliquen també una extensió de la pròpia noció de dependència envers la seguretat o la protecció d'altres aspectes ben valorats de la vida (com ara la qualitat del medi ambient o la qualitat de les relacions socials). La dependència és, doncs, multidimensional i, per tant, en cada cas concret de risc es poden donar diversos tipus de racionalitzacions, fins i tot contradictòries.

social, els quals han suggerit que un important factor que determina les percepcions de risc és el fet que la gent senti que controla la seva vida, en lloc de sentir-se controlat per altres.

13. En la bibliografia es troben descripcions de casos on la gent no ha protestat davant els riscos als quals estava exposada (Jupp i Irwin, 1989), sense que això signifiqui que es confiava en els experts o en els gestors del risc.

14. En una recerca sobre la percepció del risc laboral dels pesticides a Catalunya (Espluga, 2001), s'observa com la majoria dels pagesos estudiats presenten un risc de contaminació molt elevat, però posen en pràctica uns comportaments marcadament insegurs, amb nombroses conseqüències (danys) visibles sobre la seva salut. Però, tot i que aquesta situació els genera uns nivells d'angoixa i preocupació considerables, no per això deixen de treballar de manera insegura, la qual cosa fa que es continuïn intoxicant sense remei. Els pagesos manifesten el seu rebuig a la utilització de pesticides, així com la seva desconfiança respecte als fabricants, venedors i experts en agroquímics, però, malgrat tot, mantenen l'adhesió a aquestes pràctiques (promogudes per agències estatals i empreses del sistema agroindustrial), perquè en tenen una dependència molt forta. 


\section{Conclusions}

L'emergència durant el darrer terç del segle XX dels debats sobre els riscos ambientals motivà la proliferació de mètodes i d'activitats encaminats a analitzarlos, avaluar-los i gestionar-los de la millor manera possible. Aquests mètodes d'avaluació i de gestió dels riscos s'insereixen en el marc d'un paradigma dominant que considera el coneixement expert com l'única font vàlida per servir de guia a la presa de decisions en aquestes matèries. Tot plegat va fer que les persones no conformes amb la gestió dels riscos passessin a ser considerades com una mena de porucs ignorants que calia convèncer i reconduir vers l'objectivitat dels fets definits científicament. En aquest context apareixen els estudis sobre la "percepció social del risc». Les diverses perspectives d'anàlisi aquí exposades responen a plantejaments teòrics i metodològics (i ideològics) diferents, sovint poc congruents entre si, però han generat un corpus de coneixements que contribueixen a fer més entenedors alguns aspectes de les respostes socials als riscos tecnològics. En podríem destacar alguns:

- Resulta evident que entre experts i profans sovint hi ha diferents percepcions, experiències i expectatives respecte als riscos.

- Es constata que no sempre hi ha relació entre la percepció dels beneficis que genera una activitat i la percepció dels riscos que comporta.

- L'intent de buscar nivells objectius de risc acceptable s'ha revelat com a poc encertat, ja que el que la gent accepta no són riscos sinó opcions (i els riscos poden formar part d'algunes d'aquestes opcions).

- Diferents grups socials poden desenvolupar diferents percepcions del risc en funció de la seva adhesió a determinades normes socials i valors culturals de referència. A més a més, el temor a un risc pot tenir la conseqüència indirecta (volguda o no volguda) de contribuir a cohesionar un grup social (és a dir, el risc pot ser funcional al manteniment d'un determinat ordre social).

- Es poden identificar algunes característiques que poden influir en els comportaments individuals de risc, com ara la «involuntarietat de l'exposició», la "familiaritat amb el risc», la «controlabilitat de les conseqüències», l'aparició «diferida dels danys en el temps o en l'espai», etc. No hi ha acord, això no obstant, sobre si són atributs cognitius o característiques del context social d'interacció.

- El fet que uns individus no protestin contra un risc no implica que l'acceptin. És possible que les seves relacions de dependència (social, psicològica, econòmica, etc.) amb certes institucions (implicades en la generació del risc) els impedeixin manifestar el seu rebuig.

- Per entendre els comportaments dels individus davant un risc, no n'hi ha prou amb conèixer les seves percepcions individuals, sinó que caldria analitzar el context de relacions socials en el qual tenen lloc aquells comportaments, així com tenir en compte les dimensions institucionals (credibilitat, confiança, percepció d'injustícia o d'inequitat, etc.) que conformen el procés de risc. En aquest sentit, cal tenir en compte que quan una persona avalua 
un risc, implícitament fa una valoració també de les institucions que el promouen i el gestionen, i emet un judici sobre la credibilitat i la confiança que li mereixen.

Moltes de les noves tecnologies (o factors de risc) inclouen grans àrees d'incertesa, ignorància o indeterminació, que dificulten la presa de decisions mitjançant el model clàssic de gestió de riscos. Aquesta incertesa, immaterialitat i invisibilitat de les amenaces afavoreix que molt del coneixement al respecte depengui d'estimacions subjectives i d'interpretacions (expertes). I tota interpretació depèn d'uns valors i constitueix inevitablement una perspectiva política $\mathrm{i}$ ideològica. La inevitabilitat de la interpretació de molts dels riscos els fa contínuament oberts a la definició i a la construcció socials, tot i que no es poden construir de qualsevol manera, ja que hi ha unes constriccions derivades d'aspectes materials, socials i culturals. Això confereix un estatus especial, i un poder important, als agents socials que es troben en disposició de definir (i/o legitimar) els riscos: científics, polítics, mitjans de comunicació, legisladors. La definició d'aquests tipus de riscos tecnològics, en conseqüència, respon sempre a unes determinades relacions de poder, i, evidentment, els grups $\mathrm{i}$ interessos que dominen l'arena política reclamaran la legitimitat exclusiva d'unes particulars formes expertes de coneixement.

Des d'aquesta perspectiva, tot reprenent la qüestió que plantejàvem en la introducció de l'article, intentar resoldre les respostes socials davant els riscos tecnològics mitjançant "més i millor informació» no deixa de ser una manera d'ocultar aquest context de relacions de poder. Es podria concloure que l'existència de protestes ciutadanes (o respostes socials, o conflictes socioambientals) als riscos tecnològics, més que (o a més a més de) com una manifestació de temor a danys ambientals o a la salut humana, poden ser enteses com una demanda de més transparència en els processos de decisió, d'una distribució més equitativa (i justa) dels riscos (i dels beneficis) que generen aquelles tecnologies, així com de garanties de més respecte als estils de vida i a les xarxes de relacions (a les identitats socials) de la població que es veu més afectada pels riscos. En aquest context, les respostes socials als riscos tecnològics són símptomes de l'exigència ciutadana de més transparència, equitat i justícia a les institucions públiques o privades encarregades de gestionar els riscos, la qual cosa no es pot resoldre només proveint informació a la població.

\section{Bibliografia}

AMATO, V. (1995). Rischio tecnologico, ambiente e territorio. Nàpols: Edizioni Scientifiche Italiane.

AMENDOLA, G. (1991). "Qualità della vita, bene comune, rischio accettabile: topoi retorici e/o strettoie concettuali della valutazione di impatto ambientale». A BEATO, F. (a cura de). La valutazione di impatto ambientale. Un approccio integrato. Milà: Franco Angeli, p. 20-37.

Bauman, Z. (1991). Modernity and Ambivalence. Cambridge: Polity Press. 
BeCK, U. (1992). Risk Society. Towards a New Modernity. Londres: Sage [1986].

- (1998). Politicas ecológicas en la edad del riesgo. Antídotos. La irresponsabilidad organizada. Barcelona: El Roure [1988].

DAKE, K. (1991). «Orienting dispositions in the perception of risk. An analysis of contemporany worldviews and cultural biases». Journal of Cross-cultural Psychology, 22, núm. 1: 61-82.

DOUGLAS, M. (1996). La aceptabilidad del riesgo según las ciencias sociales. Barcelona: Paidós [1985].

Douglas, M.; Wildavsky, A. (1982). Risk and Culture. Berkeley, Los Angeles, Londres: University of California Press.

Espluga, J. (2001). «Percepción del riesgo y uso de pesticidas en la agricultura». Ecología Política, 22, p. 17-30.

- (2002). «Fenòmens NIMBY: Les respostes socials a les antenes de telefonia mòbil». A DD.AA. Observatori del Risc: Informe 2002. Barcelona: IDES.

FischHOFF, B.; Slovic, P.; LichtensteIn, S. (1981). «Lay Foibles and Expert Fables in Judgements about Risk». A O'Riordan, T.; TuRNER, R.K. (eds.). Progress in Resource Management and Environmental Planning, vol. 3. Chichester: Wiley, p. 161-202.

FischHofF, B.; Slovic, P.; Lichtenstein, S.; ReAD, S.; CoOMBS, B. (1978). «How Safe is Safe Enough: A Psychometric Study of Attitudes towards Technological Risk and Benefits». Policy Sciences, núm. 8: 127-152.

Giddens, A. (1993). Las consecuencias de la modernidad. Madrid: Alianza [1990].

- (1995). Modernidad e identidad del yo. Barcelona: Península [1991].

GutiérReZ, J.; BAjén, M.J.; Ferré, P.; Bonell, E. (1991). «Actitud de la población hacia la energía nuclear». A De CASTro, R. (comp.). Psicología Ambiental: Intervención y Evaluación del Entorno. Sevilla: Arquetipo Ediciones.

- (1993). "Progreso, seguridad y actitud hacia la industria petroquímica». Revista de Psicología General y Aplicada, 46 (1): 101-106.

JuPP, A.; IRWIN, A. (1991). "Emergency response and the provision of public information under CIMAH: a case study». Disaster Management, 4, 1 (1989), 33-37.

KASPERSON, R.E. (1992). «The Social Amplification of Risk: Progress in Developing an Integrative Framework». A KRIMSKY, S.; GoldING, D. (eds.). Social Theories of Risk. Westport i Londres: Praeger, p. 153-177.

Kasperson, R.E.; Renn, O.; Slovic, P.; Brown, H.S.; Emel, J.; Goble, R.; Kasperson, J.X.; Ratick, S. (1988). "The Social Amplification of Risk: A Conceptual Framework». Risk Analysis 2, núm. 8: 177-187.

Lichtenstein, S.; SlOvic, P.; FischHOfF, B.; LAYMAN, M.; COMBS, B. (1978). «Judged Frequency of Lethal Events». Journal of Experimental Psychology 6, núm. 4: 551-578.

Oppe, S. (1988). «The Concept of Risk: A Decision Theoretic Approach». Ergonomics 4, núm. 31: 435-440.

O’Riordan, T. (1983). «The Cognitive and Political Dimensions of Risk Analysis». Journal of Environmental Psychology, núm. 3: 345-354.

Otway, H. (1985). «Introduction». A OTWAY, H.; Peltu, M. (eds.). Regulating Industrial Risks. Londres: Butterworth.

Otway, H.; Cohen, J.J. (1975). «Revealed Preferences: Comments on the Starr Benefit-Risk Relationships», International Institute for Applied Sustems Analysis Research Memorandum, p. 75-80.

Otway, H.; Fischbein, M. (1976). «The Determinants of Attitude Formation: An Aplication to Nuclear Power». International Institute for Appllied Systems Analysis Research Memorandum, p. 76-80. 
Otway, H.; Von Winterfeldt, D. (1982). «Beyond Acceptable Risk: On the Social Acceptability of Technologies». Policy Sciences, núm. 14: 247-256.

Pidgeon, N.; Hood, C.; Jones, D.; Turner, B.; GiBSON, R. (1992). «Risk Perception». A The Royal Society (eds.). Risk: Analysis, Perception and Management. Report of a Royal Society Study Group. Londres: The Royal Society.

PuY, A. (1995). Percepción social de los riesgos. Madrid: Mapfre.

RAYNer, S. (1990). Risk in Cultural Perspective: Acting Under Uncertainty. Norwell: Kluver.

Renn, O. (1991). "Risk Communication and the Social Amplification of Risk». A KASPERSON, R.E.; STAllen, P.J.M. Communicating Risks to the Public: International Perspectives. Dordrecht: Kluwer Academic Publishers, p. 287-324.

- (1992). "Concepts of risc: A Classification». A Krimsky, S.; Golding, D. (eds.). Social Theories of Risk. Westport i Londres: Praeger, p. 53-81.

Slovic, P. (1987). "Perception of Risk». Science, núm. 236: 280-285.

Slovic, P.; Fischhoff, B.; Lichtenstein, S. (1984). «Behavioural Decision Theory Perspectives on Risk and Safety». Acta Psychologica, núm. 56: 183-203.

Stallen, P.J.M.; Tomas, A. (1988). «Public Concern About Industrial Hazards». Risk Analysis 2, núm. 8: 237-245.

STARR, C. (1969). "Social Benefit versus Techonological Risck». Science, núm. 165: 1.232-1.238.

TÀBARA, J.D. (1995). La percepció dels problemes de medi ambient. Barcelona: Beta. TuRnER, G.; WYNNE, B. (1992). «Risk communication: a literature review and some implications for biotechnology». A Durant, J. (ed.). Biotechnology in Public. A Review of Recent Research. Londres: Science Museum for the European Federation of Biotechnology, p. 109-141.

Vlek, C.; Stallen, P.J. (1980). «Rational and Personal Aspects of Risk». Acta Psychologica, núm. 45: 273-300.

Wynne, B. (1980). "Technology, Risk and Participation: on the Social Treatment of Uncertainty». A Conrad, J. (ed.). Society, Technology and Risk. Londres, Nova York: Academic Press, p. 87-103.

- (1982). Rationality and Ritual: The Windscale Inquiry and Nuclear Decisions in Britain. Chalfont St Gilles: British Society for the History of Science.

- (1989). «Frameworks of Rationality in Risk Management: Towards the Testing of Naive Sociology». A Brown, J. (comp.). Environmental Threats: Perception, Analysis and Management. Londres, Nova York: Belhaven Press, p. 33-47.

- (1992a). "Risk and Social Learning: Reification to Engagement». A KRIMSKY, S.; Golding, D. (eds.). Social Theories of Risk. Westport, Londres: Praeger, p. 275-299.

- (1992b). "Misunderstood misunderstanding: Social Identities and Public Uptake of Science». Public Understanding of Science 3, núm. 1: 281-304.

- (1996). "May the Sheep Safely Graze? A Reflexive View of the Expert-Lay Knowledge Divide». A LASH, S.; SZERSZYNSKI, B.; Wynne, B. Risk, Environment and Modernity. Londres: Sage, p. 44-83. 